\title{
PAŽENGUSIO ŠIRDIES NEPAKANKAMUMO ETIOLOGIJOS, DIAGNOSTIKOS IR GYDYMO YPATUMAI
}

\author{
Emilija Bernotaitè ${ }^{1}$, Diana Žaliaduonytè $\dot{e}^{1,2,3}$ \\ ${ }^{I}$ Lietuvos sveikatos mokslu universiteto Medicinos akademijos Medicinos fakultetas, \\ ${ }^{2}$ Lietuvos sveikatos moksly universiteto ligoninès Kauno kliniku Kardiologijos klinika, \\ ${ }^{3}$ Respublikine Kauno ligonine
}

Raktažodžiai: pažengęs širdies nepakankamumas, diagnostika, širdies transplantacija, mechaniniai kraujotaką palaikantys prietaisai.

\begin{abstract}
Santrauka
Širdies nepakankamumo (toliau - ŠN) gydymas per keletą pastarujų dešimtmečių buvo papildytas naujais medikamentais ir intervencinèmis priemonèmis, pratęsiančiomis sergančiųjų širdies ligomis gyvenimą, tačiau mirštamumo rodikliai vis tiek nepaprastai dideli. Tinkamas ligos gydymas gali suletinti, sustabdyti arba kai kuriais atvejais pakeisti ŠN progresavimą, tačiau net ir taikant efektyviausią medikamentinị gydymą, ŠN gali progresuoti iki galutinès stadijos, kai gydymas tampa nebeveiksmingas, o kruopščiai atrinktų pacientų grupei dar galima širdies transplantacija. Darbo tikslas - atrinkti ir išanalizuoti ekspertu nustatytas ir visuotinai pripažintas pažengusio (terminalinio) ŠN priežastis, diagnostikos bei gydymo rekomendacijas.
\end{abstract}

\section{Ivadas}

2016 metų Europos kardiologų draugijos ūminio ir lètinio širdies nepakankamumo diagnostikos ir gydymo gairèse ŠN apibūdintas kaip klinikinis sindromas, kurị sukelia struktūrinè ir (ar) funkcinè širdies liga, lemianti sistolinio tūrio sumažęjimą ir spaudimo širdies ertmèse padidejimą ramybès būklëje, ar krūvio metu [1]. Ligos pradžioje dažniausiai nepastebima jokių pokyčių, tačiau jai progresuojant, simptomai ryškejja. ŠN būdingi tipiniai simptomai bei požymiai yra dusulys, nuovargis, kulkšnių edemos, skysčių kaupimasis organizme [2]. Amerikos kardiologų kolegijos ir Amerikos širdies asociacijos (ACCF/AHA) parengtos suaugusiujjų širdies nepakankamumo diagnostikos ir gydymo gairès nurodo keturias klinikines ŠN stadijas [3]:

- A stadija - didele ŠN rizika, nesant struktūrinès širdies ligos ir ŠN simptomų;
- B stadija - struktūrinè širdies liga, išlikusi sistolinè kairiojo skilvelio (toliau - KS) funkcija, nesant ŠN simptomų;

- C stadija - struktūriné širdies liga su sutrikusia sistoline KS funkcija ir ŠN simptomais;

- D stadija (pažengęs arba atsparus gydymui ŠN) - medikamentiniam gydymui atsparus ŠN , reikalingas specialių intervencijų.

Pasaulyje ŠN serga 26 milijonai žmonių, iš kurių maždaug 5 proc. nustatoma D stadija [4]. Tai svarbi pacientų grupè, nes sergančiųjų D stadijos ŠN vienerių metų mirtingumas gali siekti net iki 75 procentų [5]. Sergantiesiems D stadijos ŠN, dažniausiai tenka taikyti pažangesnius gydymo metodus, tokius kaip specialios skysčių šalinimo procedūros (pvz., hemofiltracija), nuolatinis inotropiškai veikiančių medikamentų skyrimas, mechaninių kraujo apytakos palaikymo prietaisų implantavimas ar širdies transplantacija [6]. Nepaisant optimalaus gydymo medikamentais, ŠN D stadija pasižymi progresuojančiais ir (arba) sunkiais ŠN simptomais, dažnai pasikartojančiomis S̆N dekompensacijomis ir stacionarizavimu, sunkiu širdies funkcijos sutrikimu $[2,7]$. Pacientai skundžiasi dusuliu ramybès metu arba esant minimaliam fiziniam krūviui, nuovargiu, tinimais, dispepsijos simptomais, kacheksija, nerimu, depresija [8]. Nors šiuolaikinès medikamentinio, elektrofiziologinio ir chirurginio gydymo galimybės gerokai padidino sergančiųjų lètiniu ŠN išgyvenamumą, veiksmingiausias gydymo metodas, kai kitos galimybės jau išnaudotos, yra širdies transplantacija.

Darbo tikslas - atrinkti ir išanalizuoti ekspertų nustatytas ir visuotinai pripažintas pažengusio (terminalinio) ŠN priežastis, diagnostikos bei gydymo rekomendacijas.

\section{Tyrimo medžiaga ir metodika}

Atlikta mokslinių straipsnių paieška elektroninèse duomenų bazėse PubMed, Wiley Online Library ir ScienceDirect, naudojant raktažodžius. Atrinkti ir išnagrinèti naujausi temą atitinkantys tyrimai. 
Etiologija. Pacientų, sergančių ŠN, ligos etiologija gali būti ịvairi. Dažniausios ŠN priežastys - išeminè širdies liga (vainikinių arterijų liga, miokardo infarktas), vaistai, toksinai (alkoholis, kokainas, amfetaminas, chemoterapiniai vaistai), infekcinès ligos (limfocitinis miokarditas, milžiniškų ląstelių miokarditas), medžiagų apykaitos ligos (tirotoksikozè, anemija, mitybos trūkumas (pvz., beriberio liga), infiltracinès ligos (sarkoidozè, amiloidozè), su širdies perkrova susijusios ligos (arterinè hipertenzija, vožtuvų pažeidimai, hipertrofinė kardiomiopatija, arterioveninès anomalijos/fistulès), aritmijos (tachiaritmija, bradiaritmija, aritmogeninè dešiniojo skilvelio kardiomiopatija) ir kitos ligos (genetikos nulemtos, raumenu distrofija) [8]. Daugeliui pacientų būdinga ne viena, o kelios skirtingos patologijos - ne tik širdies ir kraujagyslių ligos, kurios gali sukelti ŠN. Diagnozuojant ŠN, svarbu nustatyti etiologiją, nes kai kuriais atvejais pašalinus ligos priežastis ir parinkus tinkamą gydymą, galima tikètis geresnès pacientų sveikatos prognozès [2].

Diagnostika. Tobulejjant technologijoms, atsirandant naujų vaistų, radosi naujų diagnostikos bei gydymo rekomendacijų poreikis, todèl $2016 \mathrm{~m}$. Europos kardiologų draugijos iniciatyva buvo parengtos naujos ūminio ir lètinio širdies nepakankamumo diagnostikos ir gydymo gairès [2]. Gairèse nurodyta, kad įtarus ŠN, svarbu įvertinti ŠN diagnozès tikimybę, remiantis ligos ir gyvenimo anamneze, šeimine anamneze. Reikia išsiaiškinti, ar pacientas sirgęs MI, ar jam atlikta revaskuliarizacija, kiek metų serga arterine hipertenzija (toliau - AH), ar vartojo diuretiku, ar kardiotoksinių medikamentų, ar yra pasireiškęs naktinis dusulys ar ortopnejja. Rekomenduotina atlikti išsamų fizinį ištyrimą, užrašyti ramybės elektrokardiografiją (toliau - EKG). Objektyviai vertinant būklę, tikslinga nustatyti, ar nèra stazinių karkalų plaučiuose, ịvertinti, ar negirdimi širdies patologiniai ǔžesiai, ar yra kulkšnių edemos, ar neišsiplètusios juguliarinès venos. Jei visi objektyvūs duomenys normos ribose, nèra pakitimų EKG, ŠN diagnozè mažai tikètina. Jei nenormalus bent vienas rodiklis, reikia ištirti natriurezinių peptidų koncentraciją kraujyje - smegenų natriuretinį peptidą (BNP) ar neaktyvų prohormoną - smegenų natriuretini peptidą (NT-pro-BNP). Normali jų koncentracija kraujyje leidžia atmesti ŠN diagnozę. Tačiau, jei NT-pro-BNP $\geq 125$ pg/ml, $\mathrm{BNP} \geq 35 \mathrm{pg} / \mathrm{ml}$, rekomenduojama atlikti echokardiografiją ir ịvertinti širdies funkciją [2].

2018 m. Europos kardiologų draugijos Širdies nepakankamumo asociacijos ekspertų priimtame sutarime, kuris paruoštas remiantis ịvairiais moksliniais tyrimais ir klinikine praktika, pateikti atnaujinti pažengusio ŠN diagnostikos kriterijai $[9,10]$ :

1. Sunkūs ir nuolat progresuojantys ŠN simptomai (Niujorko širdies asociacijos (toliau-NŠA) III arba IV klasè);
2. Sunkus širdies funkcijos sutrikimas, kai:

- sumažejusi KS išstūmio frakcija (toliau - KSIF) $\leq 30$ proc.,

- arba izoliuotas dešiniojo skilvelio funkcijos sutrikimas (pvz., aritmogeninè dešiniojo skilvelio kardiomiopatija),

- arba neoperuojami sunkūs vožtuvų pakitimai,

- arba igimtos anomalijos,

- arba nuolatos padidejjusios (arba vis didejjančios) BNP arba NT-pro-BNP reikšmès ir nustatomi echokardiografiniai rodikliai, rodantys sunkią diastolinę disfunkciją ar KS struktūrinę anomaliją, kai yra išlikusi ir vidutiniškai sutrikusi KSIF.

3. Skysčių sąstovio simptomai mažajame ar didžiajame kraujo apytakos rate, kai reikalingas gydymas intraveniniais diuretikais ar jų deriniais, arba mažo sistolinio tūrio (hipoperfuzijos) nulemti simptomai ir inotropinę širdies funkciją gerinančių vaistų poreikis, ar pasikartojančios gyvybiškai reikšmingos aritmijos, dèl kurių buvo reikalingas 1 ar daugiau apsilankymų pas gydytoją arba stacionarizavimas dèl šių priežasčių per pastaruosius 12 mènesių.

4. Sunkus fizinio pajègumo sutrikimas, kai žmogus negali sportuoti ar 6 MET $(<300 \mathrm{~m})$, ar $\mathrm{pVO}_{2}(<12-14 \mathrm{ml} / \mathrm{kg} / \mathrm{min}$.), nulemtas širdinès kilmès patologijos.

Diagnozuojant paženguși ŠN, turi būti nustatyti visi aukščiau išvardinti kriterijai. Svarbūs ir kitų organų funkcijos sutrikimai bei gretutinès ligos (pvz., kacheksija, kepenų ar inkstų funkcijos sutrikimas), kurių buvimas lemia blogesnę klinikinę būklę ir prognozę sergantiems progresuojančiu lètiniu ŠN [9,11-12]. Gali būti nustatoma ir 2 tipo plautinè hipertenzija, tačiau šie kriterijai nèra privalomi diagnozuojant pažengusi ŠN [9]. 1 ir 4 kriterijai dažnai tinka ne tik tiems pacientams, kuriems yra širdies disfunkcija (t.y. yra ir 2 kriterijus), bet ir tiems, kurie turi kitą patologiją (pvz., sunki plaučių liga, neširdinè cirozė arba mišrios etiologijos inkstų liga). Dèl pažengusios gretutinès ligos šių pacientų gyvenimo trukmè ir išgyvenamumas riboti, neretai ribotos ir gydymo galimybès. Juos reikia nuodugniai ištirti, diagnozuoti ligas, tačiau gydymo galimybès, įskaitant intervencinius S̆N gydymo metodus, gali būti labai ribotos $[9,10]$. Diagnozavus ŠN, reikia nustatyti priežastị sukèlusią ligą ir pradèti tinkamą gydymą.

Gydymo principai. Dar visai neseniai pacientams, sergantiems galutinès stadijos ŠN , atspariu medikamentiniam gydymui, buvo mažai galimybių pratęsti gyvenimą ir pagerinti funkcinę būklę. Vis dèlto pastarujų metų medicinos ir farmacijos technologijų pažanga teikia pacientams nauju vilčių.

Gydant ŠN, siekiama palengvinti simptomus, pagerinti pacientų funkcini pajègumą ir gyvenimo kokybę, išvengti pakartotino hospitalizavimo ir sumažinti mirštamumą. Europos 
kardiologų draugijos rekomendacijose patariama gydymui skirti angiotenziną konvertuojančio fermento inhibitorius (toliau-AKFI)/angiotenzino II receptorių blokatorius (toliau - ARB) ir beta adrenoreceptorių blokatorius (toliau - BAB), tačiau jei išlieka simptomai skiriant maksimaliai toleruojamas AKFI/ARB ir BAB dozes, reikia prideti mineralkortikoidų receptorių antagonistus (toliau - MRA). Nustatyta, kad AKFI, BAB ir MRA gerina sergančiujjų ŠN, esant sumažèjusiai kairiojo skilvelio išstūmio frakcijai (toliau - KSIF), išgyvenamumą. Jei simptomai išlieka, gydymas gali būti papildytas angiotenzino receptorių ir neprilizino inhibitoriais (toliau - ARNI), selektyviais specifiniais sinoatrialinio mazgo $I_{f}$ jonų srovès inhibitoriais (ivabradinu), arba gali būti sprendžiama dẻl širdị resinchronizuojančio gydymo taikymo. Esant stazės simptomų ir (ar) požymių, diuretikai turètų būti skiriami kartu su šiame skyrelyje aprašytais vaistais. Jei nepakanka BAB, ar jie negalimi, dažnio retinimui papildomai galima skirti digoksino [2]. Nei diuretikai, nei digoksinas pacientų išgyvenamumo negerina, o tik mažina simptomus. Nepaisant taikyto optimalaus medikamentinio gydymo ar intervencinių metodų, tokių kaip sẻkminga revaskuliarizacija ar širdị resinchronizuojantis gydymas, daliai pacientų išlieka ženkli ŠN klinika, todèl jiems širdies transplantacija gali būti vienintelis gydymo būdas [13]. Nors širdies transplantacija ir išlieka aukso standartu gydant gydymui atsparų ŠN,

1 lentelè. Širdies transplantacija: indikacijos ir kontraindikacijos KMI - kūno masès indeksas

\begin{tabular}{|c|c|}
\hline $\begin{array}{l}\text { Pacientai, kuriems } \\
\text { gali būti atlikta šir- } \\
\text { dies transplantacija }\end{array}$ & $\begin{array}{l}\text { 1. Sergantieji galutinės stadijos ŠN. Sun- } \\
\text { kūs simptomai, bloga prognozė, nèra kitų } \\
\text { gydymo galimybių. } \\
\text { 2. Motyvuoti, gerai informuoti ir emociškai } \\
\text { stabilūs. } \\
\text { 3. Gebantys ištverti gydymą, reikalingą po } \\
\text { operacijos. }\end{array}$ \\
\hline Kontraindikacijos & $\begin{array}{l}\text { 1. Aktyvi infekcija. } \\
\text { 2. Sunki periferinių arterijų ar smegenų } \\
\text { kraujagyslių liga. } \\
\text { 3. Negrižtama plautinė hipertenzija. } \\
\text { 4. Onkologinès ligos. } \\
\text { 5. Negrižtamas inkstu funkcijos sutrikimas } \\
\text { (pvz., kreatinino klirensas }<30 \mathrm{ml} / \mathrm{min} \text {.). } \\
\text { 6. Sisteminè liga, pažeidžianti kelis orga- } \\
\text { nus. } \\
\text { 7. Kita svarbi gretutinė liga, kurios bloga } \\
\text { prognoze. } \\
\text { 8. Prieš transplantaciją KMI }>35 \mathrm{~kg} / \mathrm{m}^{2} \text {. } \\
\text { 9. Dabartinis alkoholio ar narkotikų var- } \\
\text { tojimas. } \\
\text { 10. Nepakankama socialinè parama, rei- } \\
\text { kalinga užtikrinti tinkamą ambulatorinę } \\
\text { priežiūra. }\end{array}$ \\
\hline
\end{tabular}

tačiau donorų pasiūla yra daug mažesnė už paklausą visame pasaulyje [14]. Kyla pacientų atrankos klausimas (1 lentelè). Europos kardiologų draugija pripažista, kad širdies transplantacija, palyginti su įprastiniu ŠN gydymu, ne tik gerokai pagerina sergančiujų galutinès stadijos ŠN išgyvenamumą, bet ir gyvenimo kokybę $[2,15]$. Transplantuotų pacientų stebėsenos duomenys rodo, kad praejus 1-3 metams po širdies transplantacijos operacijos, net 90 proc. išgyvenusiujų gali mégautis normaliu, aktyviu gyvenimu [16]. Po širdies persodinimo kyla transplantuotos širdies atmetimo rizika, todèl skiriamas imunosupresinis gydymas vaistais. Pradžioje pooperaciniam imuninès sistemos slopinimui (indukcijai) skiriami interleukino-2 receptorių antagonistai, polikloniniai ar monokloniniai antikūnai, palaikomajam antisupresiniam gydymui dažniausiai naudojamas trijų imunosupresinių vaistų derinys - kalcineurino inhibitoriai (ciklosporinas ar takrolimas), antimetabolitai (mikofenolato mofetilis ar azatioprinas) arba ląstelių ciklo inhibitoriai (sirolimas ar everolimas) ir gliukokortikoidai [17]. Vartojant imunosupresinius vaistus, galimas jų šalutinis poveikis, pvz., infekcijos, antikūnų sukelta atmetimo reakcija, vèlyvo transplantato disfunkcija, piktybiniai navikai, inkstų funkcijos sutrikimas, hipertenzija, cukrinis diabetas [16].

Daugejja pacientų, kuriems būdingi dekompensuoto ŠN simptomai, laukiančių širdies transplantacijos. Pirmenybė teikiama esant skubių indikacijų, t.y. taikomas nuolatinis intravenininis gydymas inotropiškai veikiančiais vaistais (kardiogeninis šokas), užsitęsęs IV NŠA funkcinès klasès ŠN, atsparus optimaliam medikamentiniam gydymui, kai $\mathrm{KSIF}<20$ proc., o didžiausias deguonies sunaudojimas $\mathrm{VO}_{2}$ $<10 \mathrm{ml} / \mathrm{kg} / \mathrm{min}$;; pasikartojanti nestabili miokardo išemija sergantiems IŠL, kuri negali būti koreguota perkutanine ar chirurgine revaskuliarizacija; pasikartojanti gyvybei pavojinga aritmija; didelè mirties rizika pagal ŠN išgyvenamumo rodiklį HFSS (Heart failure survival score), kuris apskaičiuojamas įvertinant kardiomiopatijos tipą (išeminè ar ne), širdies susitraukimų dažnį ramybės metu, kairiojo skilvelio išstūmimo frakciją, vidutinị kraujospūdi, yra ar nèra intraventrikulinio laidumo sutrikimo, maksimalų $\mathrm{O}_{2}$ sunaudojimą $\left(\mathrm{VO}_{2} \max \right)$ ir natrio kiekị serume $<7,19$. Esant lètinei, sunkiai, progresuojančiai ŠN eigai, yra rizika, kad pacientai nesulauks donoro širdies ir transplantacijos, todèl svarbu tinkamai įvertinti kontraindikacijas. Kai kuriais atvejais jas galima vertinti kaip reliatyvias, o ir vertinimas gali pasikeisti, jei tai buvo išgydomos ligos, pvz. I-II stadijos vèžys po sèkmingo gydymo, nutukimas, gyvensenos keitimas. Ruošiantis širdies transplantacijai ar po jos, labai svarbi visapusė artimujų parama ir palaikymas, paciento sąmoningumas, vaistų nuolatinis vartojimas, šeimos gydytojo, kardiologo, kardiochirurgo stebejiimas po operacijos. 
Siekiant pagerinti sunkios būklès pacientų išgyvenamumą ir gyvenimo kokybę iki širdies persodinimo, gali būti taikomas mechaninių kraujotaką palaikančių prietaisų (toliau MKPP) implantavimas. Dažniausiai tai yra širdies skilvelius pavaduojančių prietaisų sistemos (toliau - SPP), naudojamos kaip tiltas ị širdies transplantaciją, nes pagerina tinkamai parinktų potencialių širdies recipientų išgyvenamumą iki transplantacijos [18]. Nuo $2001 \mathrm{~m}$. kai kuriose šalyse dèl donorų trūkumo MKPP taikomi ir kaip galutinis ŠN gydymas. Paskelbus REMATCH (angl. Randomized evaluation of mechanical assist in the treatment of congestive heart failure) klinikinès studijos rezultatus, irodyta, kad taikant MKPP pacientams, kuriems širdies transplantacija negalima, pagerejja sergančiujų pažengusiu ŠN išgyvenamumas, palygintas su tais, kuriems skiriamas tik optimalus medikamentinis gydymas [2,5,13]. Europos kardiologų draugija sergančiųų $\breve{S} N$ pacientų ištyrimo ir gydymo gairèse nurodo nuolatinès tėkmès skilvelius pavaduojančiu prietaisu (toliau - SPP) tinkamumo kriterijus (2 lentelè). Jie gali būti naudojami neribotą laiką, kol bus persodinta širdis.

SPP - tai dirbtiniai prietaisai, pavaduojantys kairiji (KS) ir (ar) dešiniji (DS) skilvelị, išstumiant kraują, palaikant adekvačią sisteminę ir (ar) plaučių kraujotaką. Pavaduojant $\mathrm{KS}$, kraujo tėkmė iš kairiojo prieširdžio arba KS viršūnès prietaisu nukreipiama ị kylančiąją aortą, pavaduojant dešiniji skilvelị (DS), kraujo tèkmė nukreipiama iš dešiniojo prieširdžio ị plaučių arteriją.

Pagal veikimo mechanizmą SPP skirstomi ị:

- pulsuojančios tėkmès, kurie gali būti pneumatiniai (angl. Thoratec, Abiomed, Medos) ar elektriniai (angl. HeartMate I, Novacor),

- nuolatinès tèkmès, kurie gali būti centrifuginiai (angl. BioMedicus, Terumo, Jostra, HeartMate III) ar ašiniai (angl. Novacor I, HeartMate II, MicroMed DeBakey, Arrow Lion Heart, Jarvik 2000),

- dirbtinę širdí.

Pulsuojančios tèkmès prietaisai atkartoja natūralios širdies susitraukimų pulsaciją, tačiau jie nesuderinti su širdies ritmu. Nuolatinès tėkmès prietaisai (HeartMate II, Jarvik 2000 ir kt. ) tradiciškai generuoja nenutrūkstamą, nepulsuojančią kraujo tėkmę [19-20]. Naujos kartos prietaisai, tokie kaip HeartMate III yra gerokai pažangesni. MOMENTUM 3 klinikinio tyrimo metu ịrodyta, kad šis prietaisas pranašesnis už HeartMate II, nes HeartMate III susijęs su mažesne trombozès ir insulto rizika bei didesniu išgyvenamumu per dvejus metus po prietaiso implantavimo [13,21]. Tačiau SPP implantavimo indikacijos labai ribotos, kai sunki DS sistolinė disfunkcija ar pacientas turi svarbių gretutinių ligu (pvz.: ryškus inkstų funkcijos nepakankamumas, cukrinis diabetas dekompensacijos fazèje, sunki lètinè obstrukcinè plaučiu liga, miego sutrikimai, tokie kaip obstrukcinè ir centrinè miego apnèja, ženkli anemija ir kt. sunkios būklès, nurodytos kaip širdies transplantacijos kontraindikacijos) [2,22-24]. Blogejant DS funkcijai, ar numatant, kad po SPP implantavimo DS funkcija išliks bloga, kol pacientas sulauks širdies transplantacijos, gali būti implantuojami ir biventrikuliniai SPP. Dirbtine širdis gali būti implantuota tiems pacientams, kuriems negalimas KSPP implantavimas dèl mechaninių komplikacijų, pvz.: tarpskilvelinès pertvaros ar širdies plyšimo.

SPP implantavimas yra sudètinga operacija, susijusi su galimais nepageidaujamais reiškiniais: prietaiso gedimo rizika, didesnè infekcijų, tromboembolinių ir hemoraginiu komplikacijų rizika [25-27]. Po operacijos būtinas paciento stebejjimas, nuolatinis vaistų dozių titravimas ir priežiūra III lygio širdies ir kraujagyslių centre, todèl pacientų atranka ir paciento sutikimas šiai operacijai turi būti apsvarstytas daugiadalykejje gydymo specialistų komandoje, kaip ir ruošiantis širdies transplantacijos operacijai.

Paliatyvioji pagalba. Esant blogam sergančiujų ŠN išgyvenamumui, patiriant sunkius, gyvenimo kokybę bloginančius simptomus, atsiranda sergančiujų ŠN priežiūros integravimo paliatyviają pagalbą poreikis [28]. Paliatyvioji pagalba skiriama slopinti simptomus bei ligonio kančias, kai medicininis gydymas jau nebegali padèti. Paliatyviosios pagalbos paslaugos galètų būti teikiamos gydymo ịstaigose, paciento namuose, slaugos namuose, kuriuose teikiamos stacionarinès ir ambulatorinès paliatyviosios pagalbos paslaugos [29-30]. Paliatyviosios terapijos metu pagrindinis dèmesys skiriamas ị likusio gyvenimo kokybès palaikymą ar gerinimą ir užtikrinimą orios mirties, kai tokia baigtis tampa neišvengiama. PAL-HF (angl. Palliative care in heart failure) tyrimas, kuriame dalyvavo 150 pacientų, parodé, kad skiriant paliatyvią pagalbą pacientams, sergantiems pažengusiu ŠN , stebèta akivaizdi nauda gyvenimo kokybei,

2 lentelė. Nuolatinès tėkmės skilvelius pavaduojančių prietaisų implantavimo indikacijos

KSIF - kairiojo skilvelio išstūmio frakcija, VO2 - deguonies suvartojimas, ŠI - širdies indeksas

$>2$ mèn. išliekantys sunkaus ŠN simptomai, nepaisant optimalaus medikamentinio ar kito gydymo, kai yra daugiau nei vienas is išvardytų kriterijų [2]:

- $\mathrm{KSIF}<25 \%$ ir $\mathrm{VO}_{2}<12 \mathrm{ml} / \mathrm{kg} / \mathrm{min}$.

$\bullet \geq 3$ stacionarizavimai dèl ŠN per pastaruosius 12 mèn., kai nèra aiškios pablogèjimo priežasties.

- Priklausomybė nuo intraveninių inotropinių vaistų.

- Progresuojantis sunkus organų nepakankamumas (plaučių kapiliarų pleištinis spaudimas $\geq 20 \mathrm{~mm} \mathrm{Hg}$ ir sistolinis kraujo spaudimas $\leq 80-90 \mathrm{~mm} \mathrm{Hg}$ ar $\breve{\mathrm{S}} \mathrm{I} \leq 2 \mathrm{~L} / \mathrm{min} / \mathrm{m}^{2}$ )

- Nèra sunkios dešiniojo skilvelio disfunkcijos. 
nerimo, depresijos įveikai ir dvasinei gerovei, nei skiriant tik ịprastinị ŠN gydymą [31]. Lietuvoje ŠN paliatyviosios priežiūros koncepcija dar tik kuriama.

\section{Išvados}

Didejjant sergamumui ir mirštamumui nuo ŠN , svarbu užtikrinti pacientams adekvatų šiuolaikišką medikamentinị ir, jei indikuotina, intervencini gydymą, siekiant palengvinti esamus simptomus, išvengti ligos paūmèjimo ir pagerinti gyvenimo kokybę. Labai svarbu komandinis šeimos gydytojo, kardiologo bei kitų specialybių gydytojų darbas, siekiant efektyviai gydyti pacientą. Svarbi tinkama sergančiưjų sunkiu galutinès stadijos ŠN priežiūra, kardiologo konsultavimas ir paciento siuntimas chirurginiam gydymui tinkamu laiku.

\section{Literatūra}

1. What is heart failure? https://www.heart.org/en/health-topics/ heart-failure/what-is-heart-failure

2. Ponikowski P, Voors AA, Anker SD, Bueno H, Cleland JGF, Coats AJS, et al. 2016 ESC Guidelines for the diagnosis and treatment of acute and chronic heart failure: the task force for the diagnosis and treatment of acute and chronic heart failure of the European society of cardiology (ESC) developed with the special contribution of the Heart failure association (HFA) of the ESC. Eur Heart J 2016;37(27):2129-200.

https://doi.org/10.1093/eurheartj/ehw128

3. Inamdar AA, Inamdar AC. Heart failure: diagnosis, management and utilization. Journal of Clinical Medicine 2016;5(7):62.

https://doi.org/10.3390/jcm5070062

4. Ambrosy AP, Fonarow GC, Butler J, Chioncel O, Greene SJ, Vaduganathan $\mathrm{M}$, et al. The global health and economic burden of hospitalizations for heart failure: lessons learned from hospitalized heart failure registries. Journal of the American College of Cardiology 2014;63(12):1123-33.

https://doi.org/10.1016/j.jacc.2013.11.053

5. Rose EA, Gelijns AC, Moskowitz AJ, Heitjan DF, Stevenson LW, Dembitsky W, et al. Long-term use of a left ventricular assist device for end-stage heart failure. New England Journal of Medicine 2001;345(20):1435-43.

https://doi.org/10.1056/NEJMoa012175

6. Hunt SA, Abraham WT, Chin MH, Feldman AM, Francis GS, Ganiats TG, et al. 2009 focused update in corporated in to the ACC/AHA 2005 Guidelines for the diagnosis and management of heart failure in adults: a report of the American college of cardiology foundation/American heart association task force on practice guidelines developed in collaboration with the International society for heart and lung transplantation. Journal of the American College of Cardiology 2009;53(15):e1-90.

7. Fang JC, Ewald GA, Allen LA, Butler J, Canary CAW, ColvinAdams M, et al. Advanced (stage D) heart failure: a statement from the heart failure society of America guidelines committee.
Journal of Cardiac Failure 2015;21(6):519-34.

https://doi.org/10.1016/j.cardfail.2015.04.013

8. Habal MV, Garan AR. Long-term management of end-stage heart failure. Best Pract Res Clin Anaesthesiol 2017;31(2):153-66. https://doi.org/10.1016/j.bpa.2017.07.003

9. Crespo-Leiro MG, Metra M, Lund LH, Milicic D, Costanzo MR, Filippatos G, et al. Advanced heart failure: a position statement of the Heart failure association of the European society of cardiology. Eur J Heart Fail 2018;20(11):1505-35. https://doi.org/10.1002/ejhf.1236

10. Metra M, Dinatolo E, Dasseni N. The new heart failure association definition of advanced heart failure. Card Fail Rev 2019;5(1):5-8.

https://doi.org/10.15420/cfr.2018.43.1

11. Iorio A, Senni M, Barbati G, Greene SJ, Poli S, Zambon E, et al. Prevalence and prognostic impact of non-cardiac co-morbidities in heart failure outpatients with preserved and reduced ejection fraction: a community-based study. Eur J Heart Fail 2018;20(9):1257-66.

https://doi.org/10.1002/ejhf.1202

12. Canepa M, Straburzynska-Migaj E, Drozdz J, FernandezVivancos C, Pinilla JMG, Nyolczas N, et al. Characteristics, treatments and 1-year prognosis of hospitalized and ambulatory heart failure patients with chronic obstructive pulmonary disease in the European society of cardiology heart failure long-term registry. Eur J Heart Fail 2018;20(1):100-10.

https://doi.org/10.1002/ejhf.964

13. Patel S, Nicholson L, Cassidy CJ, Wong KY-K. Left ventricular assist device: a bridge to transplant or destination therapy? Postgrad Med J 2016;92(1087):271-81.

https://doi.org/10.1136/postgradmedj-2015-133718

14. Kittleson MM, Kobashigawa JA. Cardiac transplantation: current outcomes and contemporary controversies. JACC: Heart Failure 2017;5(12):857-68.

https://doi.org/10.1016/j.jchf.2017.08.021

15. Mehra MR, Canter CE, Hannan MM, Semigran MJ, Uber PA, Baran DA, et al. The 2016 International Society for heart lung transplantation listing criteria for heart transplantation: a 10-year update. J Heart Lung Transplant 2016;35(1):1-23. https://doi.org/10.1016/j.healun.2015.10.023

16. Yusen RD, Edwards LB, Dipchand AI, Goldfarb SB, Kucheryavaya AY, Levvey BJ, et al. The registry of the International Society for heart and lung transplantation: thirty third adult lung and heart lung transplant report-2016; focus theme: primary diagnostic indications for transplant. J Heart Lung Transplant 2016;35(10):1170-84.

https://doi.org/10.1016/j.healun.2016.09.001

17. Pham M X. Induction and maintenance of immunosuppressive therapy in cardiac transplantation in adults. UpTo Date 2019 https://www.uptodate.com/contents/induction-and-maintenance-of-immunosuppressive-therapy-in-cardiac-transplantationin-adults 
18. Osaki S, Edwards NM, Velez M, Johnson MR, Murray MA, Hoffmann JA, et al. Improved survival in patients with ventricular assist device therapy: the University of Wisconsin experience. Eur J Cardiothorac Surg 2008;34(2):281-8. https://doi.org/10.1016/j.ejcts.2008.04.023

19. Samuels LE. The implantable left ventricular assist device: a bridge to a destination. J Clin Exp Cardiolog 2013;04(09). https://www.omicsonline.org/the-implantable-left-ventricularassist-device-a-bridge-to-a-destination-2155-9880.1000267. php?aid=18426 https://doi.org/10.4172/2155-9880.1000267

20. Carr CM, Jacob J, Park SJ, Karon BL, Williamson EE, Araoz PA. CT of left ventricular assist devices. Radiographics 2010;30(2):429-44. https://doi.org/10.1148/rg.302095734

21. Mehra MR, Uriel N, Naka Y, Cleveland JC, Yuzefpolskaya M, Salerno CT, et al. A fully magnetically levitated left ventricular assist device - final report. N Engl J Med 2019; 380(17): 1618-27.

https://doi.org/10.1056/NEJMoa1900486

22. Meani P, Gelsomino S, Natour E, Johnson DM, Rocca H-PBL, Pappalardo F, et al. Modalities and effects of left ventricle unloading on extracorporeal life support: a review of the current literature. Eur J Heart Fail 2017;19(2):84-91. https://doi.org/10.1002/ejhf.850

23. Gustafsson F, Rogers JG. Left ventricular assist device therapy in advanced heart failure: patient selection and outcomes. Eur J Heart Fail 2017;19(5):595-602. https://doi.org/10.1002/ejhf.779

24. Widmer F. Comorbidity in heart failure. Ther Umsch 2011;68(2):103-6. https://doi.org/10.1024/0040-5930/a000127

25. Mehra MR, Naka Y, Uriel N, Goldstein DJ, Cleveland JC, Colombo PC, et al. A fully magnetically levitated circulatory pump for advanced heart failure. N Engl J Med 2017;376(5):440-50. https://doi.org/10.1056/NEJMoa1610426

26. Mehra MR, Goldstein DJ, Uriel N, Cleveland JC, Yuzefpolskaya M, Salerno C, et al. Two year outcomes with a magnetically levitated cardiac pump in heart failure. N Engl J Med 2018;378(15):386-95.

https://doi.org/10.1056/NEJMoa1800866

27. Starling RC, Moazami N, Silvestry SC, Ewald G, Rogers JG, Milano CA, et al. Unexpected abrupt increase in left ventricular assist device thrombosis. N Engl J Med 2014;370(1):33-40.

https://doi.org/10.1056/NEJMoa1313385

28. Riley JP, Beattie JM. Palliative care in heart failure: facts and numbers. ESC Heart Fail 2016;4(2): 81-7.

https://doi.org/10.1002/ehf2.12125
29. Kavalieratos D, Gelfman LP, Tycon LE, Riegel B, Bekelman DB, Ikejiani DZ, et al. Palliative care in heart failure: rationale, evidence, and future priorities. J Am Coll Cardiol 2017; 70(15):1919-30.

https://doi.org/10.1016/j.jacc.2017.08.036

30. Yancy CW, Jessup M, Bozkurt B, Butler J, Casey DE, Drazner $\mathrm{MH}$, et al. $2013 \mathrm{ACCF} / \mathrm{AHA}$ guideline for the management of heart failure: a report of the American college of cardiology foundation/American heart association task force on practice guidelines. J Am Coll Cardiol 2013;62(16):e147-239.

31. Rogers JG, Patel CB, Mentz RJ, Granger BB, Steinhauser KE, Fiuzat M, et al. The palliative care in heart failure (PAL-HF) randomized, controlled clinical trial. J Am Coll Cardiol 2017; 70(3):331-41.

https://doi.org/10.1016/j.jacc.2017.05.030

\section{ETIOLOGY, DIAGNOSTICS AND MANAGEMENT OF ADVANCED HEART FAILURE. LITERATURE OVERVIEW E. Bernotaitè, D. Žaliaduonytė}

Keywords: advanced heart failure, diagnostics, heart transplantation, mechanical circulatory-support devices.

Summary

Although there have been significant innovations and developments in heart failure therapy, which have prolonged the lives of cardiac patients, the mortality rate of these patients still remains unacceptably high. Proper treatment of the disease can slow down, stop or in some cases reverse the progression of heart failure. However, even with the best medical care available, heart failure can progress over time to the final stage, when optimal drug treatment becomes ineffective. For a carefully selected group of these patients, cardiac transplantation is currently the definitive gold standard.

The aim of this article was to review literature data regarding the etiology of heart failure and discuss the current guidelines of advanced heart failure diagnostics and treatment.

Literature search was performed in PubMed (Medline), Wiley Online Library and ScienceDirect databases using these keywords and their combinations: advanced heart failure, diagnostics, heart transplantation, mechanical circulatory-support devices. Summarised data are presented in the article.

It should be remembered that the teamwork of family physicians, cardiologists and other specialty doctors is essential for effectiv treatment of the patient suffering from severe end stage heart failure.

Correpondence to: Diana.Zaliaduonyte@kaunoklinikos.lt Gauta 2020-02-20 